\title{
LXX. Dissociation of hydrogen and nitrogen by electron impacts
}

\section{A. LI Hughes D.Sc.}

To cite this article: A. LI Hughes D.Sc. (1921) LXX. Dissociation of hydrogen and nitrogen by electron impacts , Philosophical Magazine Series 6, 41:245, 778-798

To link to this article: http://dx.doi.org/10.1080/14786442108636268

Published online: 08 Apr 2009.

Submit your article to this journal \lceil

Q View related articles $\square$

Citing articles: 13 View citing articles 47 
LXX. Dissociation of Hydrogen and Nitrogen by Electron Impacts. By A. LL. Hughes, D.Sc., Research Professor of Physics, Queen's University, Kingston, Canada*.

\section{HYDROGEN.}

T ANGMUIR $†$ found that hydrogen could be dissociated by contact with a tungsten (or other metallic) wire when its temperature was raised above $1300^{\circ} \mathrm{K}$. He calculated from his experiments that the work necessary to dissociate a gram molecule of hydrogen was 84,000 calories. This may be expressed in terms of the energy necessary to dissociate a single molecule. It is the energy which an electron would acquire in falling through a potential difference of $3 \cdot 6$ volts.

It, occurred to the writer that possibly the molecules could be dissociated by direct impact of electrons possessing energy in excess of that corresponding to $3 \cdot 6$ volts. The experiment failed to show any appreciable dissociation by electrons whose energy corresponded to $3 \cdot 6$ volts. It, however, led to an investigation of the disappearance of hydrogen when subjected to bombardment by electrons possessing higher energies. A number of investigations have from time to time been carried out on the reduction in pressure when an electric discharge is passed through a gas. In some respects, the central idea of the present investigation is new. The experimental conditions are simplified so as to give as direct information as possible as to the ratio of the number of molecules disappearing from the gas in terms of the number of collisions between electrons and molecules, for different values of the electron velocities. A stream of electrons is passed through hydrogen and the progressive decrease in pressure noted. It is assumed, for reasons discussed later, that the hydrogen which disappears, does so, because it is dissociated into atoms which condense on the walls when they strike them.

Apparatus.-The final form of apparatus used is shown in fig. 1. The earlier experiments showed the necessity for trapping the atomic hydrogen as completely as possible. This was secured (as in some of Langmuir's experiments) by keoping the experimental tube in liquid air throughout a set of observations. This called for a source of electrons

* Communicated by the Author.

† I angmuir, Journ. Amer. Chem. Soc. xxxvii. p. 451 (1915). 
which would give out as little heat as possible in order to conserve liquid air. The experimental tube $\mathbf{E}$ was a glass tube $2 \mathrm{~cm}$. in diameter internally. The source of electrons was a platinum strip (F) $1 \mathrm{~cm}$. long and $1 \mathrm{~mm}$. wide, coated

Fig. 1.

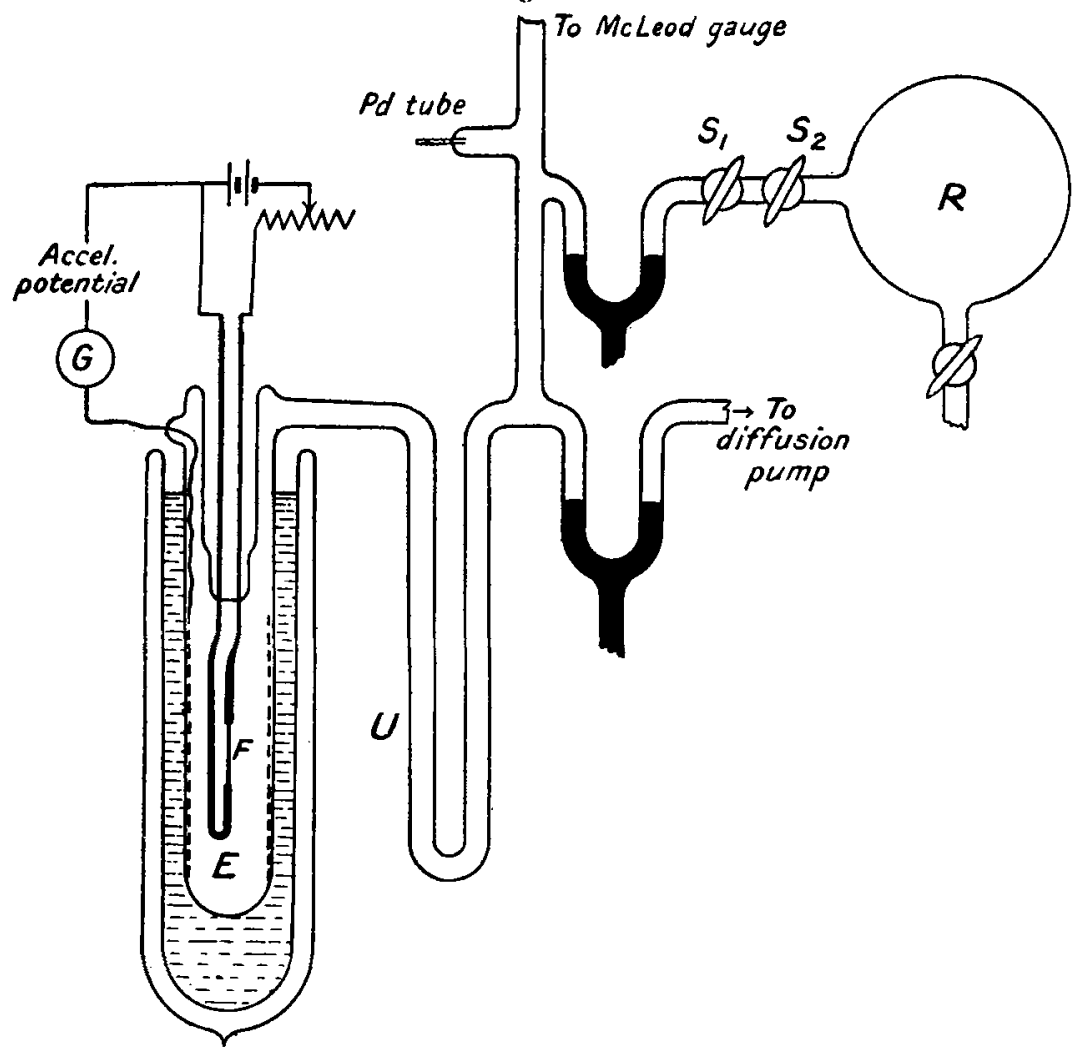

with a mixture of $\mathrm{BaO}$ and $\mathrm{SrO}$. The anode was a nickel gauze (40 mesh to the inch) which fitted snugly inside the glass tube. The advantage of this type of anode was that there were no large areas of glass surface to become charged up and give erratic results, as so often occurs when electrons and ions have an opportunity to lodge on such areas. The number of electrons available was controlled by a rheostat, while the energy of the electrons was determined by the accelerating potential applied between the gauze and the filament. The experimental tube was connected to a mercury trap and a diffusion pump through a U-tube. The 
pressure was measured by a McLeod gauge. Hydrogen was admitted through a palladium tube. 'The apparatus was thoroughly outgassed by prolonged pumping and heating to $400^{\circ} \mathrm{C}$. When systematic observations were carried out, the apparatus was subjected to an outgassing for 30 minutes at $400^{\circ} \mathrm{C}$. between each run, the filament being heated to a white heat, and the nickel gauze being bombarded by electrons. The runs tabulated below were obtained after several weeks' preliminary testing, during which there had been many short heat treatments with the pump in action, and during which no gas had been admitted except hydrogen up to pressures of from $\cdot 001$ to $\cdot 1 \mathrm{~mm}$. It is extremely unlikely therefore that there could be any impurity in the hydrogen. To keep mercury out of the experimental tube $\mathrm{E}$, it was customary, after heating both $\mathrm{E}$ and $\mathrm{U}$, to surround the U-tube with liquid air and to continue the heating and pumping for some minutes to ensure that no appreciable amount of mercury was left in $\mathrm{E}$.

Method of Experiment.-Before admitting the hydrogen, a test was always made (1) on the amount of gas given out when the filament was heated at the temperature to be used in experiment on the hydrogen, and (2) on the amount of gas given out when electrons were driven across the tube. (1) was in general not measurable, and (2) was usually very small compared with the pressure changes observed when the hydrogen was in the apparatus. Then hydrogen was admitted to approximately the pressure desired. A test was now made for the anount of hydrogen cleaned up by the hot filament--the purely thermal effect discovered by Langmuir. It was found that, at any temperature above a dull red heat, there was a very appreciable clean up. The experiments on the clean up due to the electron stream had therefore to be carried out with a lower filament temperature. Fortunately, the filament gave out an ample supply of electrons when heated to a temperature at which it was barely visible in the dark. The electrons were driven across by the accelerating potential chosen, the electron stream being held constant, if necessary, by slight adjustment of the heating current. Pressures were read every four minutes. It was impracticable to take gauge readings oftener than this. At the end of 40 minutes the electron current was stopped and the constancy of the pressure with the filament still hot, but without an electron current, was checked. The residual hydrogen was pumped out to a pressure less than $00001 \mathrm{~mm}$. Then the evolution of gas 
due to electron bombardment of the gauze was measured, using the same accelerating potential as before. This was appreciable, especially with the higher accelerating potentials and after large amounts of hydrogen had been cleaned up.

The liquid air had to be replenished from time to time, to keep its surface at the same level around the tube $\mathrm{E}$.

\section{Results.}

The clean up with different initial pressures is shown in Table I. The accelerating potential was 71 volts in every run.

\section{TABLE I.}

Electron current $=650$ microamps.

Accelerating potential $=71$ volts.

Pressures taken at intervals of 4 minutes.

\begin{tabular}{|l|l|l|l|}
\hline \multicolumn{1}{|c|}{ A } & \multicolumn{1}{|c|}{ B } & \multicolumn{1}{c|}{ C } & \multicolumn{1}{c|}{ D } \\
\hline $5080 \times 10-5 \mathrm{~mm}$ & $2160 \times 10-5 \mathrm{~mm}$ & $942 \times 10-5 \mathrm{~mm}$. & $200 \times 10-5 \mathrm{~mm}$. \\
4380 & 1602 & 642 & 122 \\
4060 & 1262 & 482 & 77 \\
3880 & 1070 & 398 & $52 \cdot 2$ \\
3550 & 926 & 338 & $\mathbf{3 5 \cdot 6}$ \\
3380 & 800 & 292 & $27 \cdot 4$ \\
3200 & 730 & 252 & $19 \cdot 2$ \\
3060 & 656 & 230 & $16 \cdot 8$ \\
2890 & 592 & 204 & $12 \cdot 4$ \\
2740 & 546 & 184 & $9 \cdot 6$ \\
2600 & 512 & 164 & $8 \cdot 8$ \\
& & & \\
\hline
\end{tabular}

The absolute amount of hydrogen cleaned up decreases as the initial pressure is made smaller, but the ratio of the initial pressure to the final pressure increases.

Table II. oives the results obtained on varying the accelerating potential, but keeping the other conditions constant. It was impossible to do more than to get the initial pressure approximately constant.

A slight but definite clean up was observed at 13.3 volts, a pressure decrease from $432 \times 10^{-5} \mathrm{~mm}$. to $408 \times 10^{-5} \mathrm{~mm}$. being observed in 60 minutes witl an electron current of 185 microamperes. ('This will be referred to as run L.) No evidence of any clean up at all could be obtained when the electrons were accelerated by 8.9 volts. A careful test was made over a period of 90 minutes, and the very slight

Phil, Mag. S, 6, Vol. 41. No, 245. May 1.921. 3 F 
TABLE II.

Electron current 650 microamperes.

Initial pressures approximately censtant.

Unit of pressure $10^{-5} \mathrm{~mm}$.

Pressure taken at intervals of 4 minutes.

Pressure.

\begin{tabular}{|c|c|c|c|c|c|c|}
\hline $\mathbf{E}$ & $\mathrm{F}$ & G & H & I & $\mathrm{J}$ & $\mathbf{K}$ \\
\hline $\begin{array}{c}291 \\
\text { volts. }\end{array}$ & $\begin{array}{c}141 \\
\text { volts. }\end{array}$ & $\begin{array}{c}71 \\
\text { volts. }\end{array}$ & $\begin{array}{c}43 \\
\text { rolts. }\end{array}$ & $\begin{array}{c}28 \cdot 3 \\
\text { volts. }\end{array}$ & $\begin{array}{r}23 \cdot 7 \\
\text { volts. }\end{array}$ & $\begin{array}{c}17.9 \\
\text { volts. }\end{array}$ \\
\hline 918 & 970 & 942 & 970 & 900 & 892 & 884 \\
\hline 656 & 636 & 642 & 730 & $7 \cdot 4$ & $7: 38$ & 796 \\
\hline 532 & 480 & 482 & 586 & 612 & 662 & 744 \\
\hline 462 & 398 & 398 & 512 & $5 \pi 2$ & 592 & 708 \\
\hline 398 & 344 & 338 & 450 & 508 & 572 & 692 \\
\hline 376 & 294 & 292 & 404 & 456 & 506 & 676 \\
\hline 344 & 264 & 252 & 364 & 414 & 480 & 662 \\
\hline 328 & 248 & 230 & 328 & 392 & 450 & 656 \\
\hline 298 & 224 & 204 & 304 & 360 & 416 & 648 \\
\hline 288 & 216 & 184 & 278 & 338 & 398 & 642 \\
\hline 270 & 200 & 164 & 252 & 318 & 380 & \\
\hline
\end{tabular}

clean up obtained was no bigger than the effect (a small thermal clean up) obtained during the next 90 minutes without an electron current.

Proportionality between electron currents and clean up.Run G was repeated with the electron current reduced fivefold. The interval between the pressure readings was increased five fold. The readings obtained were practically identical with those of run $G$, showing that the clean up. over this range of five-fold decrease in the electron current, is proportional to the electron current.

\section{The Ratio \\ Number of Hydrogen Molecules cleaned up} Let

$\mathrm{V}=$ total volume of apparatus $(=302$ c.c. $)$,

$V_{1}=$ part of volume at room temp. $(=267$ c.c. approx. $)$,

$V_{2}=" \quad$ liquid air temp. (=35 c.c. approx. $)$, $n_{1}=$ no. of molecules per c.c. in $V_{1}$,

$n_{2}=$ "
$n^{\prime}=$ total number of molecules;

then $n^{\prime}=n_{1} \mathrm{~V}_{1}+n_{2} \mathrm{~V}_{2}=n_{1}\left(\mathrm{~V}_{1}+\frac{n_{2}}{n_{1}} \mathrm{~V}_{3}\right)$

$\mathrm{N}=$ number of electrons emitted per unit time,

$\lambda=$ mean tree path of electron (in $\mathrm{V}_{2}$ ); then $\mathrm{N}\left(1-e^{-\frac{x}{\lambda}}\right) d t=\begin{aligned} & \text { number of electrons which collide with } \\ & \text { molecules between the filament and }\end{aligned}$ gauze in time $d t . \quad(x=1 \mathrm{~cm}$. 
Let $b=$ fraction of collisions resulting in disappearance of the molecule from the gas, and

$d n^{\prime}=$ decrease in the total number of molecules in $d t$.

Then $d n^{\prime}=b \mathrm{~N}\left(1-e^{-\frac{1}{x}}\right) d t$,

$$
d n_{1}\left(\mathrm{~V}_{1}+\frac{n_{2}}{n_{1}} \mathrm{~V}_{2}\right)=b \mathrm{~N}\left(1-e^{-\frac{1}{\lambda}}\right) d t,
$$

$n_{1}$ the number of molecules per c.c. in $V_{1}$ is proportional to the pressure $p$. Hence $n_{1}=a p\left(a=3.55 \times 10^{11}\right.$ at $10^{-5} \mathrm{~mm}$. pressure at $0^{\circ} \mathrm{C}$.).

Hence

$$
a d p\left(\mathrm{~V}_{1}+\frac{n_{2}}{n_{1}} \mathrm{~V}_{2}\right)=b \mathrm{~N}\left(1-e^{-\lambda} \lambda^{1} d t\right.
$$

$$
b=\frac{a\left(\mathrm{~V}_{1}+\frac{n_{2}}{n_{1}} \mathrm{~V}_{2}\right)}{\mathrm{N}\left(1-e^{-\frac{1}{\lambda}}\right)} d p
$$

Numerical values can be substituted for all the symbols on the right-hand side and so $b$ can be calculated. Before doing so, it is well to consider some possible implications of the equation. If the mean free path, $\lambda$, of an electron is considerably larger than the path $(1 \mathrm{~cm}$.) from the filament to the gauze, then the factor $\left(1-e^{-\frac{1}{\lambda}}\right)$ may be written $\frac{1}{\lambda}$, which in turn is proportional to the pressure $p$. Hence the equation becomes

$$
\begin{aligned}
b & =\frac{1}{p} \frac{d p}{d t} \times \text { const. } \\
& =\frac{d(\log p)}{d t} \times \text { const. }
\end{aligned}
$$

Now if $b$ were a constant, $i . e$. if the number of molecules disappearing always bore a constant ratio to the number of collisions, we should have $\log p$ a linear function of $t$. The results given in Tables I. and II. are shown in fig. 2 in which the ordinates are $\log _{10} p$. In no case does $\log _{10} p$ appear to be a straight line, the curves all show a decreasing rate of disappearance. This can be explained on the assumption that the surface takes up the gas which has disappeared and that as the area free to take up gas diminishes, the rate of clean up must diminish. Thus superposable curves were always obtained when starting with the same initial pressure and using the electrons of the same energy, provided that 3 F 2 
Prof. A. Ll. Hughes on Dissociation of

Fig. 2.

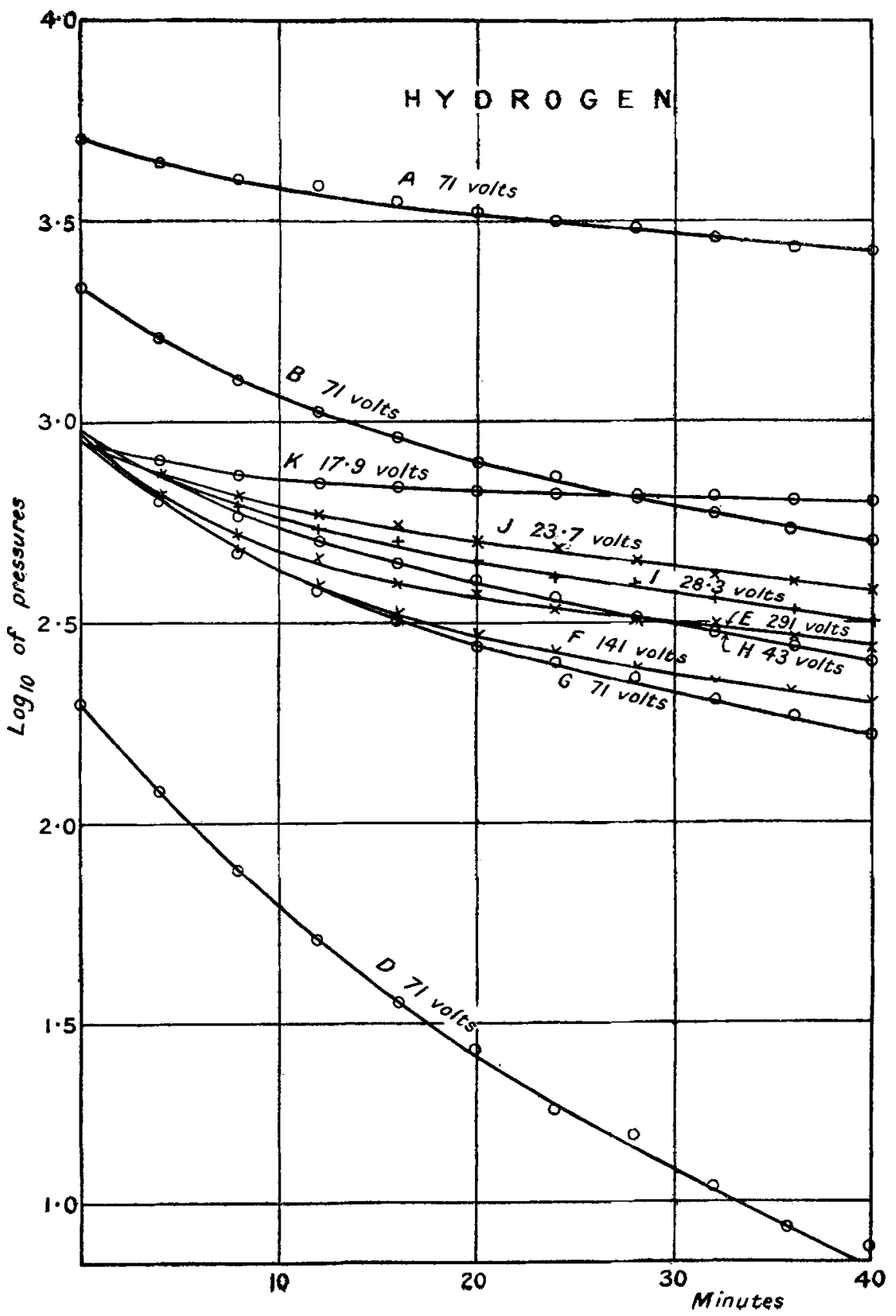


each time there had been a thorough outgassing. If the outgassing were omitted, other conditions being the same, the rate of clean up was diminished considerably. For the two lower pressures (the columns $\mathrm{C}$ and D, Table I.) the log curve corresponding to the lower pressure of the two has less curvature, as might be expected from the fact that the amount of gas which has disappeared and which retards the clean up is always less in case D than in case $C$. (C and $G$ are identical.)

To calculate " $b$ " for each run, it is clear that we must take the value of $d p / d t$ when $t=0$, for this is the time when " $b$ " is least affected by the supposed inability of the surface to take up all the dissociated gas reaching it. It was found convenient to deduce $d p / d t$ at $t=0$ from the initial slope of the corresponding log curve by means of the relation $\frac{d p}{d t}=2 \cdot 30 \frac{p d \log p}{d t}$. The pressure unit was $10^{-5} \mathrm{~mm}$., the time unit was 1 minute. $\mathrm{N}$ the number of electrons emitted in one minute was found to be $2 \cdot 44 \times 10^{1 i}$ (from the electron current of 650 microamps.).

'There remain to be calculated the free path $\lambda$ for the electron, and $n_{2} / n_{1}$ for the ratio of the densities of the gas in the parts of the apparatus at liquid air temperature and at room temperature respectively. When the mean free path of the molecule is considerably less than the distance apart of the walls of the apparatus the ordinary gas laws hold, and $n_{2} / n_{1}$ $=\rho_{2} / \rho_{1}=\mathrm{T}_{1} / \mathrm{T}_{2}$ where $\mathrm{T}_{1}$ and $\mathrm{T}_{2}$ are the absolute temperatures. However, as Knudsen* has found, when the mean free path of the molecule is considerably. less than the diameter of the tubes, another set of gas laws is applicable, from which we get $n_{2} / n_{1}=\rho_{2} / \rho_{1}=\sqrt{ } / \mathrm{T}_{1} / \mathrm{T}_{2}$. We shall refer to these two sets of laws as the high pressure, "H.P.", and the low pressure, "L.P.", laws respectively. The critical distance in this apparatus is about $3 \mathrm{~mm}$., this being the distance between the inner tube and outer tube at the level of the surface of the liquid air, for this is the place where the temperature transition occurs. (The hydrogen molecule has a mean free path of $3 \mathrm{~mm}$. at $290 \times 10^{-5} \mathrm{~mm}$. pressure at $0^{\circ} \mathrm{C.}$ )

There would have been less ambiguity if the experiments could have been carried out at pressures much below the critical values, where the "low pressure" laws apply accurately. This, unfortunately, would have meant restricting the range of observations to within a very few $\mathrm{mm}$. at the

* Knudsen, Ann. der Phys. xxxi. p. 205 (1910). 
top of the McLeod gauge. It was decided, therefore, to start at higher pressures in spite of the fact that sometimes neither set of gas laws would apply accurately :

$$
\begin{aligned}
\frac{n_{2}}{n_{1}} & =\frac{293}{90}=3.25 \text { if "high pressure" gas laws apply. } \\
& =\sqrt{\frac{293}{90}}=1.80 \text { if "low pressure" gas laws apply. }
\end{aligned}
$$

$\lambda=$ mean free path of an electron in the experimental tube at $90^{\circ} \mathrm{K}$. This was taken as $4 \sqrt{\overline{2}} \times$ m.f.p. of a molecule. There will be two values according as to whether the "high pressure" or "low pressure"" laws apply. Jeans gives $11.6 \times 10^{-6} \mathrm{~cm}$. as the m.f.p. of the hydrogen molecule at $760 \mathrm{~mm}$. pressure and $0^{\circ} \mathrm{C}$.

The values of " $b$ " calculated for runs A, B, C, and D (Table I.) are given in Table III. For the initial pressures $A$ and $B$, only the "H.P." values are admissiblc.

\section{TABLE III.}

Number of molecules disappearing.

Values of " $b "=\frac{\text { Number of molecules disappearing. }}{\text { Number of collisions between electrons and molecules. }}$

\begin{tabular}{|c|c|c|c|c|}
\hline & $d$ & $\mathbf{B}$ & $\mathrm{C}$ & D \\
\hline Initial Pressure $=$ & $\begin{array}{l}5080 \\
\times 10-5 \mathrm{~mm}\end{array}$ & $\begin{array}{l}2160 \\
\times 10-5 \mathrm{~mm}\end{array}$ & $\begin{array}{l}942 \\
\times 10-5 \mathrm{~mm}\end{array}$ & $\begin{array}{l}200 \\
\times 10-\overline{\mathrm{o}} \mathrm{mm}\end{array}$ \\
\hline$\underset{\text { mulecule }}{\text { m.f.p. of } \mathrm{H}_{2}}\left\{\begin{array}{l}\text { "H.P." law... } \\
\text { "L.P." law.... }\end{array}\right.$ & $: 053 \mathrm{~cm}$ & $\cdot 124 \mathrm{~cm}$. & $\begin{array}{l}\cdot 286 \mathrm{~cm} \\
.520 \mathrm{~cm}\end{array}$ & $\begin{array}{l}1.30 \mathrm{~cm} \\
2.45 \mathrm{~cm} .\end{array}$ \\
\hline 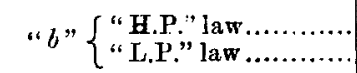 & $\cdot 129$ & $\cdot 136$ & $\begin{array}{l}\cdot 122 \\
\cdot 168\end{array}$ & $\begin{array}{c}(\cdot 115) \\
\cdot 178\end{array}$ \\
\hline
\end{tabular}

Accelerating Potential $=71$ volts.

The initial pressure in $\mathrm{C}$ is in the region where neither law is strictly applicable. The real value of " $b$ " will, therefore be between $\cdot 122$ and $\cdot 168$ for $C$. For the pressures used in D, "L.P." laws are evidently to be used and the "L.P." value of " $b$ " should be taken.

It is seen that " $b$," which measures the clean up per collision, increases progressively as the initial pressure decreases. At the lowest pressure, $D$, about 1 out of every 6 collisions results in the disappearance of a molecule. Here the conditions are the simplest, the electrons practically never make two collisions, and the atoms resulting from a collision with an electron have a good chance of reaching the walls and condensing there. 
In Table IV. the values of " $b$ " are given for approximately the same initial pressure $\left(\bumpeq 950 \times 10^{-5} \mathrm{~mm}\right.$.), but for different accelerating potentials. Runs $\mathrm{E}, \mathrm{F}, \ldots . \mathrm{K}$ (Table JI.) were used. (The initial pressure in run L, which is included, was only $430 \times 10^{-5} \mathrm{~mm}$.).

TABLE IV.

Values of " $b$."

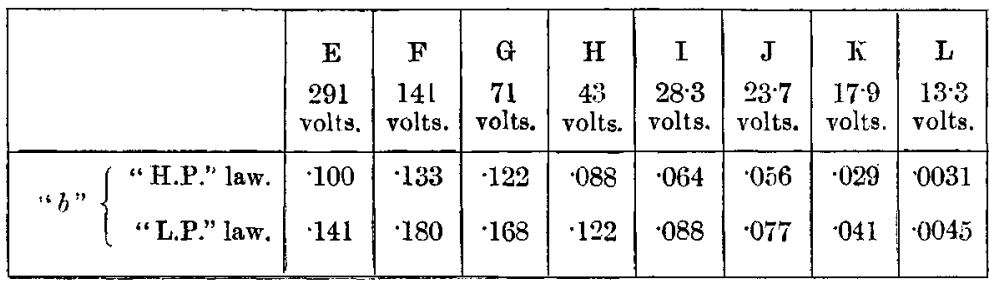

For 8.9 volts, " $b$ " could not be measured, it was certainly less than 0005 . The values for " $b$ " are shown in fig. 3 . It will be seen that " $b$ " rises rapidly between 13 and about 40 volts, and does not change much after about 60 volts. (An earlier experiment showed that " $b$ " was much the same for 600 volts as for 70 volts ; these later and more accurate experiments indicate a drop between 140 and 290 volts. It is proposed to investigate this further.)

Fig. 3.

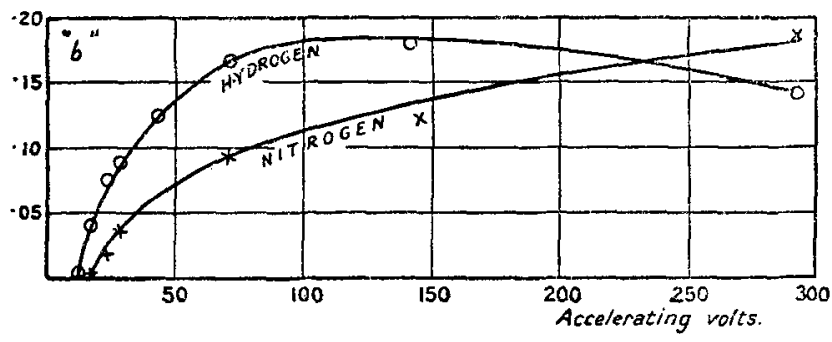

Control Experiments witli Helium.--Helium was admitted to a pressure of $950 \times 10^{-5} \mathrm{~mm}$., and a run was taken with 71 volis accelerating potential. The clean up wis liss than one two-hundredth part of that in the corresponding hydrogen run $(G)$. The helium was purified for a short time over charcoal in liquid air. The slight clean up was no doubt due to impurities, probably hydrogen, as the apparatus was not outgassed for more tlian half an hour, nor were excessive precautions taken to secure pure helium. 


\section{Discussion.}

It is necessary to give reasons for believing that the disappearance of the gas is due to dissociation of hydrogen into atoms which condense on the walls.

Langmuir * found that pure liydrogen at a low pressure in a bulb containing an incandescent filament disappeared. On carrying out the experiment with the bulb, or a side tube, immers d in liquid air, a peculiar effect wis noticed. After the pressure decrease bad been in progress for some time, the liquid air was removed (the filament heating current being cut off) and the pressure rose. On replacing the liquid air, the pressure fell a little, but not to its original value. There was. therefore, as Langmuir terms it, an nonrecondensible gas. Langmuir accounted for this on the supposition that hydrogen molecules on impact with the very hot filament were dissociated into atoms, and that these atoms, if they had a clear run to the walls, would condense on them, the effect being the more marked at low temperatures. On removing the liquid air, some of the atoms would come off and re-combine with other atoms to form molecules which could not be condensed. Thus Langmuir gives a natural explanation for the "non-recondensible" gas. The more atoms already on the surface, the greater the ctrance of an atom impinging on the surface, striking one of them and recombining to form a molecule, which leaves the surface and so reduces the apparent rate of dissociation of the gas. From experiments on the transfer of heat through hydrogen from an incandescent filament, Langmuir calculated the amonnt of hydrogen dissociated. He states that, under the most favourable conditions, the observed decrease in pressure corresponds to only $1 / 7$ of the amount actually dissociated, and may often be much less.

Non-recondensible gas was obtained in these experiments. The following is an illustration from one set of observations. Hydrogen was admitted to a pressure of $548 \times 10^{-5} \mathrm{~mm}$. and cleaned up by electron impact to a pressure of $100 \times 10^{-5} \mathrm{~mm}$. The liquid air was then removed, the pressure rose, the liquid air was replaced and the pressure fell to $263 \times 10^{-5} \mathrm{~mm}$. Hence the amount of non-recondensible gas was proportional to $(263-100) \times 10^{-5} \mathrm{~mm}$., and the amount of hydrogen which originally disappeared was proportional to $(548-100)$ $\times 10^{-5} \mathrm{~mm}$. Thus the amount of non-recondensible gas formed 37 per cent. of the amount of hydrogen cleaned, up. Then, without outgassing, more hydrogen was admitted until

* Langmuir, Journ. Amer. Chem. Soc. xxxvii. p. 451 (1915). 
the pressure was again about $550 \times 10^{-5} \mathrm{~mm}$. On repeating the experiment the yield of non-recondensible gas was 54 per cent. The procedure was carried through twice again, the yields rising to 67 per cent. and 81 per cent. 'l'hus, taking the presence of non-recondensible gas as a criterion of dissociation of hydrogen, there is strong evidence in favour of the view that hydrogen can be dissociated by electron impacts. The progressive rise in the yield corresponds to the decreasing amount of surface available for the atomic hydrogen.

Let us consider some alternative explanations. There may bo chemical action between some gaseous impurity (which must obviously be gaseous at $90^{\circ} \mathrm{K}$ ) and the hydrogen when ionized by electrons. It is extremely unlikely that the impurity would be present in sufficient quantity to account for a clean up of as much as four-fifths of the hydrogen time after time. It may be urged that hydrogen when ionized combines with the nickel, or something on it or on the glass. But in neither of these alternatives is there any reason to suppose that the compound would show the exceedingly characteristic nonrecondensible effect. We may now take up the behaviour of ionized hydrogen, which in some way may show the non-recondensible effect. 'Take first the positively charged hydrogen molecule. Such a charged molecule would be driven to the filament, and to account for the clean up found in many runs, a layer of hydrogen 100 molecules deep would be formed on the filament. Again, a clean up of this type would be unaffected by removing the liquid air if the filament were kept hot. Such was not the case. Take now the case of negatively charged hydrogen molecules. These would be driven to the gauze. If they stuck there by virtue of their charge, a very small clean up would lead to surface charge sufficient in amount to annul the field and reduce the electron current almost to zero, which is not the case. If, on the other hand, they gave up their charge, there is no reason to suppose that they would stay on the surface any more than any other uncharged molecule. Another objection is that electrons with energies less than 10 volts would be as likely to form a negative ion by uniting with a molecule as electrons with greater energies. The clean up, however, below 13 volts is very small. Still another reason against this view is that various investigations have shown that the negative ion in hydrogen is an electron, proving that there is no tendency for a hydrogen molecule to unite with an electron. 
Franck, Knipping, and Krüger * have recently published an account of the ionizing potentials of hydrogen, and they suggest that there are two types of ionization. The first type is ionization, without dissociation, when the electrons have energies in excess of 11 volts. 'The second type of ionization is accompanied by dissociation. Since $3 \cdot 6$ volts measures the energies required for dissociation and 13.5 volts measures the theoretical energy required for ionizing one atom, there should be an ionizing potential at $3 \cdot 6+13 \cdot 5=17 \cdot 1$ volts, corresponding to dissociation and ionization of one of the atoms. They verified this experimentally. Similarly they found a radiating potential at $13 \cdot 6$ volts corresponding to dissociation combined with radiation from one of the atoms $(3 \cdot 6+10 \cdot 2=13 \cdot 8$ volts $)$. They also verified the existence of an ionizing potential at $3 \cdot 6+2 \times 13 \cdot 5=30 \cdot 6$ volis, corresponding to dissociation and ionization of both atoms. On this theory, then, one would expect dissociation to accompany these types of ionization of, and radiation from, hydrogen. On account of the first type of ionization (11 volts), it is possible that all ionizing collisions are not all dissociating collisions.

Wendt $\dagger$ has found that if hydrogen is driven through a tube across which an electric discharge is passing, the hydrogen afterwards contains a small amount of triatomic hydrogen $\mathrm{H}_{3}$. In his experiments, the pressure was high enough to insure that the mean free path of a molecule was considerably less than the diameter of the tube, so it is natural to infer that the first step in the formation of $\mathrm{H}_{3}$ is the dissociation of $\mathrm{H}_{2}$ by electron impacts into atoms $\mathrm{H}$, which in turn unite with molecular hydrogen at the next collision to form $\mathrm{H}_{3}$. It is difficult to see any way of accounting for $\mathrm{H}_{3}$ without the intermediate step of the formation of $H$. Dempster $\ddagger$ has found evidence for the view that the formation of $\mathrm{H}$ is a necessary step in the formation of $\mathrm{H}_{3}$. The hydrogen spectrum contains several series (e.g., the Balmer series and the Lyman series), which are, according to Bohr's theory, characteristic of the atom. It thus appears that there are good grounds for believing that atomic hydrogen is formed in the electric discharge, and probably as a result of direct impact of electrons on molecules.

* Franck, Knipping, and Krüger, Verh. d. Deutsch. Phys. Ges, xxí. p. 728 (1919).

$\dagger$ Wendt, Nat. Acad. Sci. Proc. v. p. 518 (1919).

f Dempster, Phil. Mag. xxxi. p. 438 (1916). 
It appears then that the simplest explanation of the disappeurance of the hydrogen in this investigation is that it is due to the dissociation of the hydrogen into atomic hydrogen which condenses on the walls, especially at low temperatures. The experimental value " $b$ " for the yield of atomic hydrogen per collision is probably too low for several reasons.

(a) Some atoms may collide with other atoms forming ordinary molecular hydrogen which does not condense.

(b) Some atoms may collide with hydrogen molecules forming $\mathrm{H}_{3}$ which may not condense as readily.

(c) An atom may hit a spot on the cold surface already occupied by another atom. A hydrogen molecule will be formed and will leave the surface. Hence this dissociation does not contribute to the pressure decrease.

(d) If, after an appreciable clean up of hydrogen, the gas is completely pumped out, and electrons are accelerated so as to bombard the gauze and glass, it is found that there is a considerable evolution of hydrogen, much more than after a thorough outgassing. This effect no doubt goes on all the time during a clean up, and tends to reduce the rate of clean up, especially towards the end of a run. (This evolution due to bombardment increases, for a given electron current, with the accelerating potential, but not so quickly. Calculation shows that the total heating effect at the gauze of such a bombardment is absolutely negligible.) These effects are more clearly marked at the hicher pressures, and no doubt influence somewhat even the initial values of the clean up.

(e) It may be that not every atom which strikes a cold surface condenses. Langmuir states that the measurements of the clean up in a cold bulb in which hydrogen is being dissociated thermally by an incandescent filament, gives under the most favourable conditions a value only $1 / 7$ of the amount of dissociation actually occurring as deduced from the measurements of heat transfer through the gas. This factor is no doubt determined largely by the dimensions and shape of the bulb and the conditions of the experiment, and it would not be justifiable to multiply our experimental determination of " $b$ " by 7 to get the real amount dissociated. Nevertheless it is significant that the highest value of " $b$," viz. 18 (Tables III. and IV.), is roughly $1 / 6$ of the maximum possible yield, i.e., one dissociation per collision.

The hydrogen curve in fig. 3 shows the yield for different accelerating potentials. It attains a value not far from its maximum at abont 70-100 volts. As the electrons under 
our experimental conditions may collide with any velocity between zero and that corresponding to the applied accelerating potential, the curve which would be obtained if the electrons always collided with the energy corresponding to the applied potential would attain its maximum at a lower value, possibly somewhere between 40 and 80 volts. (One disadvantage of working at higher pressures, e.g. A in Table III., is that the electrons are forced to make most of their collisions close to the filament, so that their energies on collision are less than would be inferred from the applied field.)

On the basis of Franck, Knipping, and Krüger's view of ionization, there are good grounds for believing that ionization and dissociation of hydrogen are bound up with one another. So far as this writer knows, there are no results giving the efficiency of ionization per collision as a function of the energy of the electrons, i.e. the fraction of collisions between electrons and molecules resulting in ionizations. Johnson * has made some experiments on the total ionization produced in a gas by electrons. He found that the accelerating potential had to be raised to about 50 volts before he obtained one ion per electron passing through the gas. 'This is not quite the same thing as saying that a collision between a hydrogen molecule and an electron possessing energy corresponding to 50 volts always results in ionization, but, for want of more direct information, we may tentatively assume that an electron of such energ. will give ionization at practically every impact. If, at the higher voltages, ionization of the 17 volt type predominates, i.e. dissociation of the molecule combined with ionization of one atom, then each collision would result in the dissociation of the molecule and the production of one ion. This is what our investigation suggests, if we make use of Langmuir's result, that the rate of clean up measured, under the most favourable conditions, only one seventh of the amount of dissociation really taking place. (It is admitted that the application of Langmuir's numerical result to this investigation is open to question, but it seems certain that the cleanup measurements underestimate the amount of dissociation.) The view that the efficiency of dissociation is unity, i.e. that every collision between a molecule and an electron will result in dissociation when the electron has enough energy, has an attractive simplicity. 
No measurable amount of dissociation could be obtained when electrons of energy 8.9 volts were used. One might expect some dissociation at, or above, 3.6 volts, since this corresponds to the measured work of dissociating the hydrogen molecule. Either no dissocation at all occurs, or else it is produced in so small an amount as not to be detected in these experiments. The latter would demand very special circumstances, either in the momentary state of the hydrogen molecule, or in its orientation at impact, to give dissocation at these low values. The alternative view is that dissociation cannot occur until radiation of the proper type (the 13.5 volt effect, corresponding to dissociation and radiation from one atom) or ionization (the $17 \cdot 0$ volt effect corresponding to dissociation and ionization of one atom) takes place, $i$.e. dissociation by electron impacts must accompany some other effect.

The "clean up" of hydrogen by say an electric discharge in the presence of sodium or potassium, is probably due to combination between the metal and the atomic hydrogen produced. It is possible that lining the experimental tube with sodium would show a more rapid clean up than in the experiment if the chemical forces were stronger than the forces controlling temperature condensation.

\section{Nitrogen.}

Preparation.-Nitrogen was prepared by warming a solution of ammonium chloride and sodium nitrite. Ten litres were collected over water. This was passed slowly through calcium chloride, soda lime, red-hot copper turnings, and phosphorus pentoxide, into a reservoir $R$ of one litre capacity permanently attached to the apparatus (fig. 1). Several litres of the nitrogen were used to wash out the apparatus before finally filling the reservoir. Small quantities of nitrogen could be admitted into the apparatus by manipulating the stopcocks $\mathrm{S}_{1}$ and $\mathrm{S}_{2}$.

Method of Experiment. - Experiments were conducted in the same way as those on hydrogen.

\section{Results.}

The clean up of nitrogen for different accelerating potentials is shown in Table $V$. The experiments on nitrogen were not as extensive as those on hydrogen. No experiments have, up to the present, been carriod out on the effect of varying the initial pressure. 


\section{TABLE V.}

Electron Ourrent 650 microamps.

Initial Pressures approx. const.

Unit of pressure $=10^{-5} \mathrm{~mm}$.

\begin{tabular}{|c|c|c|c|c|c|c|c|c|}
\hline \multirow{3}{*}{$\begin{array}{l}\text { Time } \\
\text { interval } \\
\text { (mins.). }\end{array}$} & \multicolumn{6}{|c|}{ Exp. tube $\mathbf{E}$ in liquid air. } & \multicolumn{2}{|c|}{$\begin{array}{c}\text { Exp. tube at } \\
20^{\circ} \mathrm{C} \text {. }\end{array}$} \\
\hline & M & $\mathbf{N}$ & 0 & $\mathbf{p}$ & $\mathbf{Q}$ & $\boldsymbol{R}$ & $\mathbf{s}$ & $\mathrm{T}$ \\
\hline & $\begin{array}{c}291 \\
\text { volts. }\end{array}$ & $\begin{array}{c}145 \\
\text { volis. }\end{array}$ & $\begin{array}{c}72 \\
\text { volts. }\end{array}$ & $\begin{array}{c}29 \\
\text { volts. }\end{array}$ & $\begin{array}{l}23 \cdot 8 \\
\text { volts. }\end{array}$ & $\begin{array}{l}17 \cdot 8 \\
\text { volts. }\end{array}$ & $\begin{array}{c}72 \\
\text { volts. }\end{array}$ & $\begin{array}{c}72 \\
\text { volts. }\end{array}$ \\
\hline & 596 & 566 & 520 & 520 & 552 & 650 & 900 & 890 \\
\hline 3 & 364 & 376 & $\mathbf{3 7 6}$ & 456 & 520 & 650 & $662^{*}$ & 724 \\
\hline 3 & 288 & 304 & 294 & 416 & 494 & 630 & 580 & 642 \\
\hline 3 & 244 & 264 & 264 & 392 & 464 & 630 & 532 & 578 \\
\hline 3 & 212 & 224 & 234 & 382 & 444 & 612 & 480 & 532 \\
\hline 3 & 181 & 204 & 208 & 348 & 420 & 612 & 444 & 506 \\
\hline 5 & 14 & 176 & 192 & 316 & 404 & 600 & 392 & 450 \\
\hline 5 & 11 & 162 & 166 & 282 & 388 & 586 & 354 & 404 \\
\hline 5 & 101 & 141 & 144 & 274 & 37 & $\mathbf{5 8 0}$ & 318 & 376 \\
\hline 5 & 94 & $1 \div 2$ & 132 & 260 & 848 & 580 & 392 & 344 \\
\hline 5 & 88 & 112 & 128 & 255 & 344 & 572 & $260^{*}$ & 328 \\
\hline
\end{tabular}

* The firet and last time intervals in $S$ were 4 mins. The other intervals were as shown in the first column.

Runs $\mathrm{S}$ and $\mathrm{T}$ were taken under different conditions from the rest. In run $S$ the whole apparatus was at room temperature so that mercury vapour had access to the experimental tube. In run $\mathrm{T}$ the $\mathrm{U}$-tube was surrounded by liquid air to freeze out mercury from the experimental tube. The initial pressures were chosen so as to give the electrons much the same mean free path as in the runs $M, N, \ldots R$.

\section{The Ratio $\frac{\text { Number of Nitrogen Molecules cleaned up }}{\text { Number of Collisions between Electrons and Molecules }}$.}

The value of " $b$ " given in Table VI. was calculated for nitrogen in exactly the same way as for hydrogen. The calculations of various mean free paths were based on the value given by Jeans in his 'Dynamical Theory of Gases,' viz. $5 \cdot 7 \times 10^{-6} \mathrm{~cm}$. at $760 \mathrm{~mm}$. pressure and $0^{\circ} \mathrm{C}$.

It was rather surprising that the clean up without liquid air around the experimental tube (runs $S$ and $T$ ) were as great as they were. 
Hydrogen and Nitrogen by Electron Impacts.

Table VI.

Values of " $b$ " for nitrogen.

\begin{tabular}{|c|c|c|c|c|c|c|c|c|}
\hline & $\begin{array}{c}\text { M } \\
291 \\
\text { volts. }\end{array}$ & $\begin{array}{c}\mathrm{N} \\
145 \\
\text { volts. }\end{array}$ & $\begin{array}{c}0 \\
72 \\
\text { volts. }\end{array}$ & $\begin{array}{c}\mathbf{P} \\
29 \\
\text { volts. }\end{array}$ & $\begin{array}{c}\text { Q } \\
238 \\
\text { rolts. }\end{array}$ & $\begin{array}{c}\mathrm{R} \\
17 \cdot 8 \\
\text { volts. }\end{array}$ & $\begin{array}{c}S \\
72 \\
\text { volts. }\end{array}$ & $\begin{array}{c}\mathrm{T} \\
72 \\
\text { volts. }\end{array}$ \\
\hline “b" " H.P." Law & $\cdot 141$ & .095 & .070 & .028 & 0135 & .0019 & $\cdot 11$ & $\cdot 091$ \\
\hline " b" “ L.P." Law & $\cdot 186$ & $\cdot 123$ & .094 & $\cdot 038$ & 0185 & .0025 & & \\
\hline $\begin{array}{l}\text { m.f.p. for mole- } \\
\text { cule. } \\
\text { “ H.P." Law .. } \\
\text { “ L.P.” Law ... }\end{array}$ & \multicolumn{6}{|c|}{$\begin{array}{l}.24 \mathrm{~cm} . \\
.44 \mathrm{~cm}\end{array}$} & \multicolumn{2}{|c|}{$48 \mathrm{~cm}}$. \\
\hline
\end{tabular}

Fig. 4.

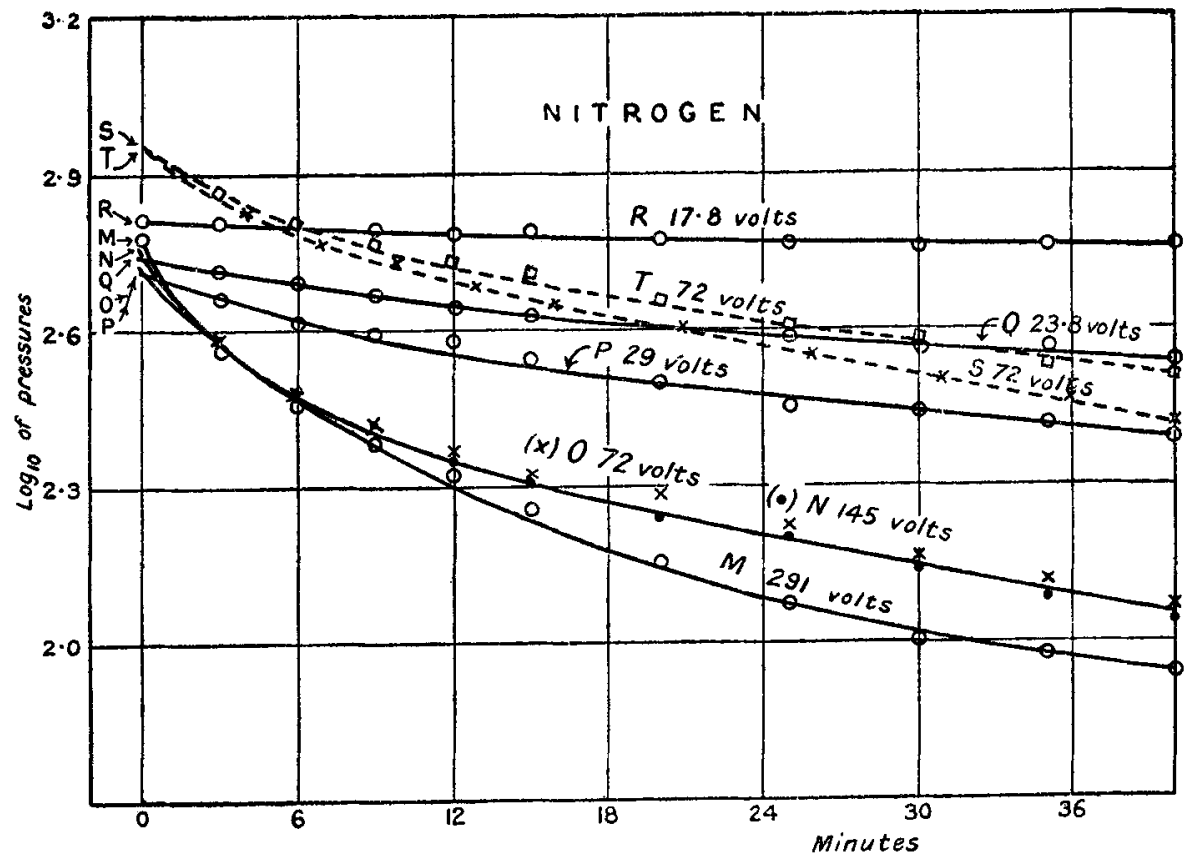

The values for " $b$ " for runs $\mathrm{M}, \mathrm{N}, \ldots \mathrm{R}$ are plotted in fig. 4 , 


\section{Discussion.}

Strutt* found that nitrogen from a discharge-tube bad active properties, and concluded that it was atomic nitrogen rather than a more complex type of molecule. He mentions that no reduction in pressure was observed when the discharge-tube was immersed in liquid air during the passage of the current. Wendt and Grubbt have shown that $\mathrm{N}_{3}$ exists in a stream of nitrogen drawn through a dischargetube. (As in Wendt's experiments on hydrogen, the gas was at a higher pressure than in these experiments, a condition which favours collisions of atomic nitrogen with molecular nitrogen to form $\mathrm{N}_{3}$.) No temperature dissociation of nitrogen such as Langmuir found for hydrogen has been observed. Hence we have nothing to give us an idea of how much the clean-up method underestimates that amount of dissociation of nitrogen (should this be the explanation for the clean up).

The strongest evidence for the view that nitrogen is dissociated in these experiments is that the "non-recondensible" effect was obtained. Thus, after a thorough outgassing, the ratio of the non-recondensible gas to the amount cleaned up was 16 per cent.; after admitting more nitrogen without outgassing, and repeating, the ratio rose to 31 per cent. ; and on repeating the procedure for a third time the ratio amounted to 67 per cent. Less nitrogen was recovered as a rule than in the corresponding experiments on hydrogen. In one experiment, with both the tubes surrounded by liquid air during the clean up, $25 \mathrm{cu} . \mathrm{mm}$. (referred to atmos. press. and temp.) were "lost" after a considerable clean up, on warming up to room temperature. On warming the tubes to $180^{\circ} \mathrm{C}$. for 20 minutes, $7 \cdot 1 \mathrm{cu} . \mathrm{mm}$. were recovered (nearly all of which came off in the first five minutes). On warming to $265^{\circ} \mathrm{C}$. for 20 minutes, $2 \cdot 9 \mathrm{cu}$. $\mathrm{mm}$. came off, and on further "arming for 20 minutes to $390^{\circ} \mathrm{C}$, $6.1 \mathrm{cu} . \mathrm{mm}$. came off. In both the latter cases, as in the first, the evolution was about complete in the first five minutes. Thus, in all, $17 \cdot 1 \mathrm{cu}$. $\mathrm{mm}$. were recovered, out of the $25 \mathrm{cu}$. $\mathrm{mm}$. which had disappeared. These results show that the nitrogen disappearing during a clean up clings rather tenaciously to the walls of the apparatus even at fairly high temperatures.

Attention is called to the large values of " $b$ " for runs $\mathrm{S}$ and $\mathrm{T}$, where there was no liquid air around the experimental tube to accelerate the clean up, as was thought

* Strutt, Proc. Roy. Soc. lxxxv. p. 219 (1911).

+ Wendt and Grubb, Science, lii. p. 159 (1920). 
would happen from analogy with hydrogen. When mercury vapour is prevented from reaching the experimental tube by immersing the U-tube in liquid air, a slightly smaller value for " $b$ " is obtained (compare runs $\mathrm{S}$ and $\mathrm{T}$ ). Passibly mercury vapour in the experimental tube helps to "fix" the atomic nitrogen as it is formed.

It will be noticed (fig. 3) that the value of " $b$ " for" nitrogen is considerably smaller than for hydrogen, as long as accelerating potentials below 200 volts are considered. At higher potentials the nitrogen curve crosses the hydrogen curvo.

It is proposed to extend these investigations further. The evidence so far obtained points to the desirability of working at very low pressures, when the simplest conditions are obtained. Possibly a Knudsen gauge or an ionization gauge will be more satisfactory than a McLeod gauge.

A peculiar clean-up effect.-The first experiments on nitrogen gave very erratic results. These were traced down to an effect which was obtained with nitrogen, but not with hydrogen. If the filament in $\mathrm{E}$ were kept warm (i.e., at any temperature above a barely visible red heat) and the tube $\mathrm{E}$ surrounded by liquid air, the pressure remained absolutely steady provided that there was no electron current. If the filament heating current were cut oft, the pressure fell slowly. In one experiment, the pressure fell from $32 \times 10^{-5} \mathrm{~mm}$. to $4 \times 10^{-5} \mathrm{~mm}$. in 120 minutes. On heating the filament, the initial pressure was regained in so short a space of time as $30-40$ seconds (the liquid air was being around the tube all the time). This cycle of events could be repeated indefinitely, and the initial pressure could always be regained by a short heating. A saturation effect was shown in this type of clean up. Thus, starting with a pressure of $4060 \times 10^{-5} \mathrm{~mm}$. with liquid air around the tabe und the filament at a dull red heat, it fell to $3120 \times 10^{-5} \mathrm{~mm}$. in five minutes after cutting off the heating current. The fall in the next fifteen minutes was only to $3040 \times 10^{-5} \mathrm{~mm}$. On heating the filament for less than a minute, the pressure rose to the initial value $4060 \times 10^{-5} \mathrm{~mm}$. The ehange of pressure due to cooling the tubes by liquid air was only that corresponding to the temperature change. Hence this effect is located at the filament. The only substances in this experiment that can account for this type of clean up are platinum, $\mathrm{BaO}$, and $\mathrm{SrO}$, and possibly the copper leads to the platinum. The effect calls for further investigation.

Plil. Mag. S. 6. Vol. 41. No. 245. May 1921. $3 \mathrm{G}$ 


\section{Summary.}

The disappearance of hydrogen and nitrogen at low pressures when an electron stream is passed through them has been investigated. For hydrogen, no disappearance was obtained unless the electrons had energy above 13 volts. 'The rate of disappearance rose rapidly as the energy of the electron was increased to about 70 volts, after which no rapid change was noted (the rate appeared to diminish somewhat when the energy of the electrons was raised from 150 to 300 volts). For nitrogen, the rate of disappearance was at first much less than for hydrogen, but when the energy of the electrons was raised sufficiently (roughly 200 volts) the rate of disappearance of the nitrogen exceeded that for hydrogen.

Reasons are given for believing that this disappearance is due to the splitting of the molecules into atoms when electrons collide with the molecules, and that these atoms condense on the adjacent surfaces particularly if they are cold. The maximum rate of disappearance of hydrogen occurred when electrons of energy corresponding to 140 volts were used. About one molecule disappeared for every six collisions. Langmuir's work on the thermal dissociation of hydrogen showed that the clean up, even under the most favourable circumstances, accounted for only one-seventh of the amount of dissociation. Hence it is possible that when the electrons have the right amount of energy a dissociation may occur almost at every collision.

A peculiar clean up, apparently due to absorption of nitrogen by a platinum filament covered with $\mathrm{BaO}$ and $\mathrm{SrO}$ when cooled to the temperature of liquid air, was noticed.

The author wishes to express his thanks to Mr. A. E. Harkness for his assistance in taking some of the observations.

Physics Department, Queen's University,

Kingston, Ont. Cunada.

December, 1920. 